\title{
People's Health Movement: A Call to Action on Nutrition, Food Security and Food Sovereignty
}

\section{Who we are and what we stand for}

- $\quad$ The People's Health Movement (PHM) is a global network of grassroots health activists and health practitioners, civil society organizations and academic institutions, particularly from developing countries. PHM currently has a presence in more than 70 countries, ranging from small groupings to well-established circles with their own governance structures. PHM works towards the revitalisation of Comprehensive Primary Health Care (CPHC) as enunciated in the Alma-Ata Declaration of 1978. PHM also works to address the social determinants and social determination of health including, in particular, the growing inequality within and between nations, driven by unfair economic structures that lock people into poverty and poor health.

- PHM works to enhance collaboration among professionals, researchers, practitioners and citizens engaged in various aspects of nutrition and food, such as undernutrition, obesity and related communicable and non-communicable diseases; also, on the changing food environment and economic and political factors affecting it. In particular, PHM works to catalyze public interest civil society action to support community-based and non-governmental organisations in their efforts to improve nutrition and reshape the policy landscape to achieve healthier, more equitable and sustainable food systems.

- PHM increasingly focuses on the 'double burden of malnutrition' where the persistence of under-nutrition and micro-nutrient deficiencies, especially among young children and pregnant and lactating women in the poorest communities, is accompanied by an alarming increase in overweight and obesity. The seeds of this double burden of malnutrition are sown at an early age by several factors, including the reduction in the proportion of infants who are being exclusively breastfed. This phenomenon is closely linked to the aggressive marketing of breastmilk substitutes by transnational corporations (TNCS) that are exploiting new markets among the urbanising populations in low- and middle-income countries (LMICs).

- PHM insists that it is indispensable to identify and address the violations of the right to adequate, nutritious and safe food that systematically result in hunger, malnutrition and related diseases, many of them affecting small-scale food producers, marginalized urban and rural workers, social groups suffering from discrimination, women and children in poor communities, and the unemployed. PHM works on the basis that many of the world's poor are also smallholder farmers. Their livelihoods are increasingly threatened by the commercialisation and monopolisation of seed and other agricultural inputs by a small number of giant TNCs, as well as by unfair trade in agricultural products resulting in the flooding of LMIC markets, increasing 'land grabs', speculation on food futures and climate 
change. Movements such a 'La Via Campesina', whose base is smallholder and indigenous farmers, have responded by mobilising around food sovereignty.

\section{An overview of our analysis}

- There are common roots underlying both under and 'over-nutrition' in our globalized world. These pertain to the impact on food systems of current practices related to food production, processing, manufacture, distribution, trade and commerce, as well as to the power differentials between those who are most affected by and those who benefit most from the current food system.

- The unregulated penetration of food and beverage companies and the aggressive marketing of processed and ultra-processed foods have been severely compounding the problem of malnutrition and the underlying food insecurity. This process is driven by mega agribusiness conglomerates and transnational food and beverage corporations through the employment of technologies and practices that are energy intensive and ecologically unsustainable, and that are also implicated in environmental degradation and climate change.

- Although the role of poverty, underdevelopment and Big Food and Beverage are recognised by the major agencies working in the field of nutrition, there is a reluctance to identify the social, economic and political determinants of this situation, as well as the key strategies and actions to address it. Such recognition will inevitably lead to a critique of neoliberal globalisation and the central role of TNCs in driving this.

- Similarly, there is increasing awareness among consumers, especially the middle classes in high-income countries, about the deteriorating food environment. Although some of them are able to take action to mitigate the effects of this and to choose a healthy diet, many, especially those rendered poor, are severely constrained in their actions by inadequate knowledge, voice and influence, including factors such as physical and financial access, lack of refrigeration to store fresh foods, and limited time and energy for food preparation.

\section{Therefore}

PHM will work with other progressive organisations to advocate for the implementation of policies that respect, protect and fulfil individuals' and groups' rights to food security and food sovereignty. These include:

- Policies on basic resources (land, water, seeds, credit); on decent jobs and living wages; on essential public services (water, sanitation, education, quality healthcare); and on social protection and social security.

- PHM further calls for the introduction of strong human rights-based regulations concerning the activities of corporations in their territories, as well as in other countries, in line with the Maastricht Principles on Extraterritorial Obligations. This includes legally binding instruments that regulate corporations that dominate all stages in the food chain and those producing and promoting ultra-processed foods and beverages that foster overweight, inadequate diets and non-communicable diseases (NCDs). 
- $\quad$ PHM calls for the participation of public interest civil society organisations to be prioritized in global and national policy discussions on nutrition and food systems.

- $\quad$ PHM further calls for policies that strongly support sustainable, climate-resilient agriculture and food systems that integrate equity, participatory and nutritional dimensions. Since gender discrimination is one of the fundamental drivers of malnutrition, PHM insists that women must be accorded full and equal land rights, as well as access to credit, capital, appropriate technologies, markets, and information. Actions to end hunger and malnutrition must work to transform societal norms detrimental to women.

- $\quad$ On food security issues, PHM will insist they be measured using indicators that ensure action and accountability towards access to adequate nutritious and safe food.

- On nutrition and food research and policy development and implementation issues, PHM insists they must remain free from conflicts of interest resulting from the undue influence of corporations and/or 'private-public-partnerships', including in the UN and especially in WHO.

- $\quad$ Breastfeeding is the most cost-effective nutrition intervention to address child malnutrition. However, it faces many barriers such as the lack of implementation of the Global Strategy on Infant and Young Child Feeding and the ongoing breaches of the International Code of Marketing of Breastmilk Substitutes and subsequent WHA resolutions. PHM calls for stronger support of the efforts to monitor and expose such breaches and to ensure effective regulation. To promote an increase in breastfeeding rates, PHM calls on States to introduce justiciable maternity entitlements and child care facilities at workplaces to support the rights of working mothers and their children.

- $\quad$ Appropriate complementary feeding must be supported by such fiscal policies as subsidies on nutritious basic foods, as well as regulating the indiscriminate global incursion of medicalised and processed ready-to-use commercial foods in young child feeding. In this regard, PHM calls upon all donors to critically reconsider product-based approaches (e.g., vitamin A capsules, ready-to-use foods, foods genetically modified to be high in one nutrient) in favour of community-based, intersectoral approaches to the prevention of all forms of malnutrition.

In sum, malnutrition in all its forms, food insecurity and the erosion of food sovereignty are all socially and politically determined. It is inadequate to acknowledge the continuing crisis of malnutrition and the inequalities it engenders without addressing their political roots and the conditions that perpetuate this. PHM takes this as its mandate.

Finally, PHM is conscious that to sustainably address malnutrition in all its forms will require a collective and concerted effort on the part of all rights holders and duty bearers. PHM thus calls on all individuals and organisations identifying with the above statement to join in developing a broad and militant campaign on the right to food and nutrition. Each organisation would preserve its own identity in such an initiative, but the need to join forces on a common platform is extremely urgent. PHM proposes that such a process begins with responses and reactions to this short document and continues at the $4^{\text {th }}$ Global Assembly of 
PHM (PHA4) in Savar (near Dhaka) Bangladesh from November 15-19, 2018. At PHA4, the issue of nutrition and food security and food sovereignty will feature as a prominent subtheme in the main body of the programme and it is intended that there will be sidemeetings to discuss a common strategy.

David Sanders, PHM co-chair

Claudio Schuftan, PHM Steering Council

Vandana Prasad, PHM India 